\title{
O SUJEITO CEREBRAL E O MOVIMENTO DA NEURODIVERSIDADE
}

Francisco Ortega

\section{Introdução}

O termo neurodiversidade foi cunhado pela socióloga australiana e portadora da síndrome de Asperger Judy Singer, em 1999, em um texto com o sugestivo título de Por que você não pode ser normal uma vez na sua vida? De um "problema sem nome" para a emergência de uma nova categoria de diferença (Singer 1999). Mas o que é a neurodiversidade, quem são os indivíduos que se referem a esse termo como critério de identificação?

Como lemos no início, "neurodiversity" — "neurodiversidade" — em Wikipedia e nas dúzias de sites dedicados ao movimento, ${ }^{1}$ é um termo que tenta salientar que uma "conexão neurológica" (neurological wiring) atípica (ou neurodivergente) não é uma doença a ser tratada e, se for possível, curada. Trata-se antes de uma diferença humana que deve ser respeitada como outras diferenças (sexuais, raciais, entre outras). Os indivíduos autodenominados "neurodiversos" consideram-se "neurologicamente diferentes", ou "neuroatípicos". Pessoas diagnosticadas com autismo, e mais especificamente portadores de formas mais brandas do transtorno - os chamados autistas de "alto funcionamento" - freqüentemente diagnosticados com a síndrome de Asperger, são a força motriz por trás do movimento. Para eles, o autismo não é uma doença, mas uma parte constitutiva do que eles são. Procurar uma cura implica assumir que o autismo é uma doença, não uma "nova categoria de diferença humana", usando a expressão de Singer (1999:63).

Para a socióloga australiana (Singer 1999), o aparecimento do movimento de neurodiversidade tornou-se possível por vários fenômenos: principalmente a influência do feminismo, que forneceu às mães a autoconfiança necessária para questionarem o modelo psicanalítico dominante que as culpava pelo transtorno autista dos filhos; a ascensão de grupos de apoio aos pacientes e a subseqüente diminuição da autoridade dos médicos, possibilitadas, sobretudo, pelo surgimento da Internet, que facilitou tanto a organização dos 
grupos, como a livre transmissão de informações sem mediação dos médicos; finalmente, o crescimento de movimentos políticos de deficientes, movimentos de autodefesa e auto-advocacia de deficientes, especialmente de surdos, que estimulou a auto-representação da identidade autista.

Se a neurodiversidade ou a "neuroatipicidade" é uma doença, então a "neurotipicidade" também o é, argumentam os adeptos do movimento. Nesse sentido, vale a pena conferir na web o irônico site do Instituto para o estudo dos neurologicamente típicos (Institute for the Study of the Neurologically Typical) (http://isnt.autistics.org). O autor do "instituto" confessa que criou o site como expressão do "ultraje autista", depois de conferir que aquilo que é escrito por "especialistas" e "profissionais" sobre o autismo é "arrogante, insultante e simplesmente errado". No site, a "síndrome neurotípica" é tida como "um transtorno neurobiológico caracterizado pela preocupação com questões sociais, delírios de superioridade e obsessão pela conformidade. Além disso, os indivíduos neurotípicos (NT) "freqüentemente assumem que sua experiência do mundo é a única ou a única correta. Neurotípicos acham difícil ficar sozinhos e, em geral, são aparentemente intolerantes às menores diferenças nos outros".

O objetivo deste site é, obviamente, desconstruir a retórica pró-cura presente, como veremos ao longo deste artigo, em muitas organizações de pais de filhos autistas e profissionais. Visa-se mostrar que o absurdo de tentar curar ou diagnosticar a "normalidade" — que aparece aqui na versão cerebral de "neurotipicidade" - é semelhante ao absurdo de se buscar curar o autismo. Por que nos chocariam as tentativas de curar a "neurotipicidade" (possibilidade apresentada ironicamente no site), enquanto aceitamos sem pensar a retórica pró-cura de associações como Cure Autism Now, Defeat Autism Now ou Autism Speaks que, no fundo, defendem uma determinada "normalidade" ou "tipicidade" cerebral? Curar um neurotípico seria o mesmo que curar um indivíduo gay, negro, canhoto ou autista, afirmam os defensores da neurodiversidade. Para eles, o autismo não é como um câncer que deva ser curado, estando mais para as tentativas de corrigir a sinistralidade ou a homossexualidade (Harmon 2004a, 2004b, 2004c). Assumir o autismo como diferença libera os indivíduos do desejo ou da necessidade da cura, o que resulta muito importante em uma época na qual existem grandes chances de dispormos, em breve, de testes genéticos que poderão impedir crianças autistas de nascer.

Em torno dos padrões autísticos de pensamento e de interesses, vem aumentando o número de páginas da internet que exprimem a "cultura autista" no seio do movimento da neurodiversidade. Ao clicarmos o termo "cultura autista" e "neurodiversidade" no Google, encontramos uma quantidade 
enorme de sites que afirmam a identidade autista (e mais especificamente Aspie, em referência à síndrome de Asperger) e celebram essa subcultura. Eles incluem desde indicações de literatura de ficção e especializada sobre os mais variados aspectos do espectro do transtorno até organizações de apoio, blogs e mecanismos de chat que facilitam a interação entre autistas, esclarecem elementos do transtorno, ajudam a compartilhar experiências e até mesmo a encontrar amigos ou futuros companheiros e cônjuges. Para a famosa autista Temple Grandin, o casamento entre autistas é natural, visto que "os casamentos funcionam melhor quando duas pessoas com autismo se casam ou quando a pessoa se casa com um deficiente ou com um parceiro excêntrico... Eles se atraem porque seus intelectos trabalham em um comprimento de onda similar" (apud Silberman 2001).

O objetivo fundamental dos movimentos é promover a conscientização e o empowerment da cultura autista, o que inclui a comemoração do "Dia do Orgulho Autista" (Autistic Pride Day) que, inspirado no Dia do Orgulho Gay, é festejado no dia 18 de junho como celebração da neurodiversidade dos autistas. ${ }^{2}$ Desde 2005 o "Dia do Orgulho Autista" teve os seguintes temas: "Aceitação, não cura" (2005); "Celebrando a neurodiversidade" (2006); "Autismo fala. É hora de escutar" (2007). No Brasil, o recém-criado movimento Orgulho Autista Brasil integra uma rede de países que comemora a neurodiversidade nessa data (Lage 2006; Caversan 2005). Prova disto é o fato de que o principal evento mundial do "Dia do Orgulho Autista" de 2005 foi realizado em Brasília. Na contramão, encontram-se, também no Brasil, as associações de pais e profissionais que buscam a cura para o autismo. As mais conhecidas são AMA (Associação de Amigos de Autistas: www.ama.org.br), AUMA (Associação de Amigos da Criança Autista: www.autista.org.br). ${ }^{3}$

A proliferação nos últimos anos dos movimentos da neurodiversidade e o aumento de sua exposição na mídia têm intensificado o embate político entre os ativistas do movimento autista e as organizações de pais e profissionais dos grupos pró-cura. ${ }^{4}$ Recentemente, os debates subiram de temperatura de forma vertiginosa. Em 2004, a publicação por Amy Harmon de uma série de artigos no New York Times sobre a neurodiversidade deu grande visibilidade ao movimento (Harmon 2004a, 2004b, 2004c). Neles, é apresentada a posição dos ativistas autistas que consideram o autismo como parte essencial do que eles são e se opõem à cura. Apesar de fazer referência também às críticas de pais e especialistas ao movimento, os artigos provocaram uma série de depreciações dos movimentos pró-cura e de pais de crianças autistas.

Numa emotiva carta aberta ao New York Times, Kate Weintraub, mãe de uma criança autista, critica a parcialidade da visão apresentada como favorável à neurodiversidade. Sua posição pode ser resumida na frase "Autismo 
é um transtorno, não é um estilo de vida ou apenas um jeito diferente de ser" (Weintraub s/d). Ela também se refere às acusações de alguns ativistas autistas que culpabilizam os pais pela situação dos filhos, os quais deveriam ser, para os mais radicais, afastados dos genitores. Os pais são "ridicularizados como 'obcecados pela cura' (curebies) ${ }^{5}$ e retratados como escravos da conformidade, tão ansiosos para que seus filhos pareçam normais que eles não conseguem respeitar sua forma de comunicação" (Harmon 2004c). Essas observações provocaram a ira de Weintraub e de outros membros dos movimentos pró-cura, para quem os ativistas "não deveriam falar como se meus filhos fossem como eles e necessitassem ser salvos de seus pais" (Weintraub s/d). Embora os movimentos autistas possuam uma retórica claramente antipsicanalista, ecoam em algumas afirmações o tom "culpabilizante" que caracteriza a visão psicanalítica sobre o autismo (Dolnick 1998). Se a psicanálise acusava os pais de crianças autistas de serem frios, obsessivos e mecânicos no tipo de atenção dada aos filhos, ${ }_{1}^{6}$ o movimento de autistas acusa-os de serem intolerantes com seu modo de ser (neuro)diferente, de não amá-los do jeito que eles "são" e de quererem falar em nome deles. Assim, os pais não estariam aflitos por causa do autismo do filho, mas pela perda do filho que esperavam e esperam poder ter (Sinclair 1993). A "parentectomy" proposta por Bettelheim ecoa nas acusações do movimento autista.

Um dos pontos mais conflitantes diz respeito à terapia cognitiva ABA (Análise Comportamental Aplicada - Applied Behavior Analysis), que para muitos pais constitui a única terapia que permite às crianças autistas realizarem algum progresso no estabelecimento de contato visual e em certas tarefas cognitivas. Para os ativistas autistas, a terapia reprime a forma de expressão natural dos autistas (Dawson 2004). A questão é acirradamente debatida no mundo anglo-saxão, já que muitos pais estão lutando na Justiça para conseguir que governos e companhias de seguros de saúde paguem pela terapia, cujo custo é muito elevado. Desse modo, os argumentos defendidos pelos movimentos da neurodiversidade de que o autismo não é uma doença e as tentativas de cura são uma afronta aos autistas, e podem fornecer razões para que seja recusado o financiamento das terapias. Este fato provoca a irritação de pais e profissionais que lutam pela implantação e pelo custeio público das terapias.

O assunto chegou aos tribunais. Várias famílias canadenses entraram em 2004 com uma ação judicial argumentando que o governo deveria pagar a terapia ABA para seus filhos por ser "medicamente necessária". Trata-se do caso Auton vs. British Columbia. Michelle Dawson, ativista autista canadense, ${ }^{7}$ questionou a ética da terapia ao ser chamada como testemunha. Este depoimento foi citado pela Suprema Corte canadense na sua decisão 
contra as famílias de filhos autistas. ${ }^{8}$ Situações como essas vêm elevando enormemente a temperatura do debate. De um lado, as famílias de autistas e suas lutas por acesso aos tratamentos e às terapias comportamentais - que implicam reconhecer o autismo como uma doença (principalmente com causas genéticas e/ou cerebrais) - para as quais os movimentos de autistas com sua retórica anticura e pró-neurodiversidade representam um ultraje às suas reivindicações. De outro lado, os ativistas autistas que consideram as terapias pró-cura um passo adiante na negação e na intolerância da diferença e da (neuro)diversidade e na implantação de políticas eugênicas e genocidas. Vejamos estes aspectos mais pormenorizadamente.

\section{Autismo: doença ou diferença?}

O historiador Charles Rosenberg observa que "entidades patológicas se tornaram atores sociais indiscutíveis, reais na medida em que temos acreditado neles e agido individualmente e coletivamente a partir dessas crenças" (2002:240). Ele chama a atenção para o "poder e [a] capacidade de penetração das entidades patológicas" e suas aparentes "estruturas neutras" (value-free frameworks) (2002:246). Estamos nos acostumando, no decorrer das últimas décadas, a negociar em público o estatuto nosológico de numerosas doenças psiquiátricas, a maioria das quais possui uma natureza problemática. Talvez o caso mais gritante dos debates acerca da legitimidade epistemológica de uma categoria de doença psiquiátrica tenha acontecido no início dos anos 1970, quando a Associação de Psiquiatria Americana decidiu votar pela inclusão ou não da categoria de homossexualidade por ocasião de uma revisão do DSM. ${ }^{9}$ Trata-se de uma doença ou de uma escolha? E se é uma doença legitimada (com uma subseqüente base biológica), como pode ser decidido por voto o seu estatuto ontológico? (Rosenberg 2002, 2006; Russo \& Venâncio 2006; Russo 2005; Russo \& Henning 1999).

Os conflitos acerca do estatuto ontológico e a conseqüente legitimidade social de doenças e transtornos mentais e as decisões acerca da etiologia, do diagnóstico e da terapêutica têm sido endêmicos na história da psiquiatria nos últimos cento e cinqüenta anos (Rosenberg 2006). Embora não exista consenso sobre numerosas doenças psiquiátricas, o fato de serem nomeadas como doenças constitui uma forma de poder e utilidade social. O diagnóstico e a eventual inclusão nos DSMs evidenciam que "a presumida existência de entidades patológicas ontologicamente reais e definidamente específicas constituiu o princípio-chave que organiza quais decisões clínicas particulares poderiam ser tomadas racionalmente" (Rosenberg 2002:239). 
Vejamos o caso do autismo: mesmo sendo reconhecido como entidade nosológica em 1980 pelo DSM-III (e a síndrome de Asperger em 1994 pelo DSM-IV), os transtornos do espectro autista vêm se tornando "categorias problemáticas", usando a expressão de Rosenberg (que a emprega para falar de "gender identity disorder", "attention déficit and hiperactivty disorder", "social anxiety disorder" e "premestrual síndrome", entre outras). É o estatuto ontológico do autismo que está sendo disputado: doença para uns, exemplo da diversidade do cérebro humano para outros.

Nos anos 1940 a 1960 predominaram as explicações psicanalíticas do autismo na teoria e na clínica psiquiátrica. De Leo Kanner (1943), no seu artigo seminal, "Os distúrbios autísticos do contato afetivo", até Bruno Bettelheim, Margareth Mahler e Francis Tustin, o autismo foi compreendido em termos de falhas no estabelecimento das relações objetais precoces do indivíduo, especialmente com os pais. Isto não quer dizer que ainda hoje não existam explicações psicanalíticas do transtorno autista, predominantemente do campo lacaniano. No entanto, é inegável que desde os anos 60 vem sendo produzido um deslocamento para explicações orgânicas, especialmente cerebrais, do transtorno, culminando em 1980 com a inclusão do autismo na rubrica de Transtornos Abrangentes do Desenvolvimento, separando-se definitivamente do grupo das psicoses infantis, na terceira edição do DSM (DSM-III).

O deslocamento do modelo psicanalítico e a aproximação com as neurociências possibilitaram que os pais fossem desresponsabilizados e desimplicados dos destinos subjetivos dos filhos (Dolnick 1998), abrindo caminho para a sua organização em associações que buscam a cura do transtorno e a implantação de terapias cognitivas e comportamentais. Para eles, o transtorno autista é uma doença com uma etiologia orgânica (principalmente cerebral e/ou genética). O estatuto orgânico do autismo legitimou o movimento. Na frase feliz de Rosenberg, "legitimidade social pressupõe identidade somática" (2006:414). Porém, o transtorno continua sendo uma categoria problemática, pois não existe consenso nem em relação à etiologia do transtorno, nem acerca da intervenção clínica mais adequada (Feinberg \& Vacca 2000).

Do ponto de vista dos ativistas autistas, as terapias constituem atentados contra a diferença e a diversidade do cérebro humano. Além disso, a possibilidade de em breve dispormos de um teste genético para detectar o risco de autismo em um feto ou embrião pode abrir a porta para que pais tenham a opção de impedir o nascimento de um filho, mesmo com as formas mais brandas do transtorno (como é a síndrome de Asperger). Nesse sentido, Arthur Caplan (2005), diretor do Center for Bioethics da Universidade de Pennsylvania, publicou em 2005 um artigo com o provocativo título de 
"Você teria permitido que Bill Gates nascesse?" ("Would you have allowed Bill Gates to be born?"), no qual sublinha o fato freqüentemente observado que Gates apresenta muitos traços de personalidade dos portadores da síndrome de Asperger, pretendendo com isso chamar a atenção para os riscos envolvidos nos testes genéticos.

Obviamente, o espectro do transtorno autista é muito amplo, abarcando desde os casos "de alto funcionamento", como (presumivelmente) Bill Gates, o filósofo Ludwig Wittgenstein e o pianista Glenn Gould, até os "de baixo funcionamento", crianças e adultos com retardo mental e severos comprometimentos cognitivos e funcionais. A meu ver, este fato nos coloca diante de importantes dilemas éticos e sociopolíticos. A questão é dupla: permitirá o teste genético estabelecer as sutilezas necessárias para definir claramente em que ponto do espectro autista o feto e/ou o embrião se encontra? Mas ao mesmo tempo, se se trata de um espectro, ou seja, um contínuo, qual deve ser o ponto de corte a determinar o nível em que o grau de comprometimento cognitivo é aceitável, mas para além dele se justificaria o aborto? Em poucas palavras, permitirá o teste genético diferenciar os autistas de "baixo" daqueles de "alto" funcionamento? Isto sem mencionar que, mesmo nos casos mais severos de autismo, não existe consenso a respeito do aborto dessas crianças, como não existe de fato em relação à síndrome de Down e a outras doenças e transtornos.

Para os ativistas do movimento autista, trata-se de um risco de genocídio que deve ser combatido. Abortar um feto autista seria como abortar um feto homossexual ou canhoto (caso fosse possível detectar essas características geneticamente). Os testes pré-natais constituem uma verdadeira ameaça eugênica que visa ao aborto dos neurodivergentes. Dada a tecnologia, pergunta Susanne Antonetta, autora de A mind apart. Travels in a neurodiverse world, diagnosticada com transtorno bipolar: "Escolheríamos apenas crianças perfeitas? Perfeitas para os olhos de quem? Nossa cultura?" (Antonetta 2005:92). A gravidade da situação levou a que ativistas do movimento entrassem em 2004 com uma petição nas Nações Unidas exigindo que, diante das ameaças, fossem reconhecidos como "grupo social minoritário", que merece proteção perante a "discriminação" e o "tratamento inumano". Eles se consideram uma minoria, uma cultura diferente com padrões de comunicação e hábitos diferentes (Nelson 2004).

Vale a pena ressaltar um elemento comum aos movimentos pró-cura e anticura. Apesar de se encontrarem num feroz embate, ambos os movimentos compartilham a recusa às explicações psicanalíticas "culpabilizantes". O deslocamento do paradigma psicanalítico para o cerebral possibilitou a organização dos dois grupos antagônicos. Para os pais de autistas, recusar a 
culpa pela doença dos filhos e a denúncia dos excessos da psicanálise está na base das primeiras associações que visam, como foi ressaltado, buscar formas de cura orientadas basicamente para a terapia comportamental e os tratamentos farmacológicos. Todavia, os anseios dos pais de autistas convergem com as explicações psicanalíticas que tratam o autismo como uma doença e/ou uma deficiência, embora se inclinem para explicações genéticas e/ou cerebrais do transtorno que exigem tratamentos farmacológicos e comportamentais, e não psicodinâmicos.

Os movimentos de autistas surgem, por sua vez, como recusa à visão negativa do autismo difundida pelas explicações psicanalíticas de Kanner, Bettelheim e outros, que focalizam a incapacidade e a deficiência. Eles convergem (nas suas posições mais radicais), no entanto, com as explicações psicanalíticas, segundo as quais as crianças autistas deveriam ser afastadas dos pais. ${ }^{10}$ A despeito das posições antagônicas de ambos os grupos em relação a considerar o autismo como doença a ser tratada ou diferença a ser tolerada e celebrada, a superação das explicações psicologizantes (psicanalíticas) constitui uma forma de empowerment tanto para os grupos pró-cura, como para os anticura. O cerebralismo do autismo é abraçado pelos dois grupos, embora leve a posições políticas antagônicas. Aplica-se a ambos a já citada observação de Rosenberg: "legitimidade social pressupõe identidade somática" (2006:414).

Para os movimentos de pais de autistas, o cerebralismo desculpabiliza-os pelo transtorno, apontando para uma causalidade concreta e objetiva que possa ser usada para reivindicar verbas públicas para a pesquisa e o tratamento de crianças autistas. Os movimentos de autistas, por sua vez, servem-se das explicações cerebrais para destacar a diversidade e a singularidade das conexões cerebrais, muitas das quais são neuroatípicas ou neurodivergentes. Refletem a diversidade do cérebro humano, que não pode ser tratada na polaridade normal/patológico ou doença/cura. Tolerância e direito à diferença e à diversidade tomam o cérebro como referência. Como observa Muskie, autor do mencionado site do Institute for the Study of the Neurologically Typical e diagnosticado com a síndrome de Asperger:

Minha bête noire atual consiste em ter consideradas minhas emoções como "rasas". Como alguém com um conhecimento consideravelmente maior sobre minhas emoções do que os "especialistas" (experts), posso declarar inequivocamente que minhas emoções não são "rasas". Pode ser que amanhã eu seja descrito como "pouco empático", ou serei ultrajado com um excepcionalmente ignorante método "de treinamento" sendo infligido a crianças autistas, ou talvez haja algum novo artigo escrito por algum especialista a partir da perspectiva de 
que a percepção neurotípica está correta e que meu cérebro é um erro genético [...] Meu cérebro é uma jóia. Eu estou espantado com a mente que tenho. Eu e minha experiência de vida não somos inferiores e podemos ser superiores à experiência de vida dos neurotípicos (ênfase minha). ${ }^{11}$

\section{Questões identitárias: ser ou ter autismo}

As associações de pais de crianças autistas negam-se a reconhecer no autismo uma questão de identidade. O autismo é uma doença, não um estilo de existência ou uma marca identitária. As crianças não são autistas, elas têm autismo, como escreve Keit Weintraub em resposta aos artigos de Amy Harmon publicados no New York Times (2004a, 2004b, 2004c):

O fato de que meus filhos têm uma anormalidade no desenvolvimento não significa que eu não os ame por quem eles são, como ela [Amy Harmon] insinua tão incessantemente. Eu amo meus filhos, mas eu não amo o autismo. Meus filhos não fazem parte de um grupo seleto de seres superiores denominados "autistas". Eles têm autismo, uma invalidez neurológica devastadora nas suas implicações em suas vidas, se não for tratado [...] Em outras palavras, não é mais normal ser autista do que é ter espinha bífida (Weintraub 2005).

Para os ativistas autistas, em contrapartida, o transtorno remete a uma questão identitária. Autismo não é alguma coisa (uma doença) que se "tem", mas algo que se "é". Não é a "concha" que aprisiona a criança normal. Não podemos separar o transtorno do indivíduo e, se fosse possível, teríamos um indivíduo com uma identidade diferente. O autismo é "impregnante, colore cada experiência, cada sensação, percepção, pensamento, emoção e encontro, todos os aspectos da existência", escreve o ativista autista Jim Sinclair (1993). Evidentemente, a posição no debate identitário determina a posição em relação à busca pela cura e às terapias. À medida que os pais de autistas falam de "ter" autismo e acolhem tentativas de cura e terapia, os movimentos da neurodiversidade apostam no "ser" autista e se opõem às tentativas de cura e às terapias cognitivas.

Como já foi assinalado, a identidade autista é vivenciada pela comunidade autista com orgulho (e comemorada no 18 de junho, o "Autistic Pride Day"). Alguns neurodivergentes usam o termo "gift" (dom) para se referirem a condições como autismo ou transtorno bipolar (Antonetta 2005). Mesmo os autistas de "alto funcionamento", que não vivenciam o transtorno como um "dom", relatam com freqüência uma sensação de "conforto" ao obterem 
o diagnóstico. "Finalmente uma explicação, finalmente uma razão para o porquê e o como", escreve John Carley ao ser diagnosticado com a síndrome de Asperger (Shapiro 2005). O filósofo Ian Hacking (2006) fala de certo tipo de paz resultante do diagnóstico de autismo; e Judy Singer remete aos "benefícios de uma identidade clara" (Singer 1999:62) de "ser" autista.

A afirmação identitária é constantemente associada ao afastamento das explicações psicológicas e das psicoterapias. Em listas de autistas, encontramos relatos recorrentes sobre o tempo e o dinheiro perdidos em sessões psicanalíticas ou psicoterápicas. O distanciamento do paradigma psicológico e a aceitação das explicações neurológicas constituem uma forma de auto-afirmação. ${ }^{12}$ Diante da "autoconsciência psicológica" (psychological self-awareness), os autistas apostam na "autoconsciência neurológica" (neurological self-awareness) (Singer 1999) e recusam o poder da psicologia. Não é um problema de trauma ou conflito, mas de uma "conexão" (wiring) cerebral diferente. Eles reclamam o direito de autodiagnóstico, e a preferência pela neurologia representa um empowerment para a cultura autista, que pode tomar as decisões por si. Graças à Internet, os autistas trocam todo tipo de informações sobre o diagnóstico e os demais aspectos do transtorno sem dependerem para isso do establishment médico.

Resulta em certo paradoxo que precisamente o cerebralismo do autismo esteja na base da afirmação identitária dos autistas ("ser" e não "ter" autismo). Além do fato de o deslocamento do modelo psicanalítico e a aproximação das neurociências terem possibilitado que os pais fossem desresponsabilizados e desimplicados dos destinos subjetivos dos filhos, a biologização (e/ou a neurologização) da doença mental - seja ela autismo, esquizofrenia, depressão, transtorno bipolar, dentre outras - leva a um distanciamento subjetivo da doença, que é tratada mais ou menos como qualquer doença física. O indivíduo é desresponsabilizado na medida em que sofre um processo de distanciamento subjetivo da doença, a qual é desestigmatizada por ser uma condição cerebral, já que para as explicações psicodinâmicas "a doença mental está na sua mente e nas suas reações emocionais a outras pessoas, é o seu 'você'" (Luhrmann 2000:6).

Quando um psiquiatra de orientação biológica fala da depressão de maneira semelhante àquela que um cardiologista fala de uma doença cardíaca, produz-se um distanciamento subjetivo da doença, uma dessubjetivação. O indivíduo tem esquizofrenia, ou transtorno bipolar, em vez de ser deprimido, esquizofrênico e/ou psicótico. Assim como o indivíduo pensa que tem uma doença cardíaca e não que ele é essa doença, no caso das doenças mentais, a depressão ou a psicose aparecem escritas no corpo - e mais especificamente no cérebro — nas descrições da psiquiatria biológica. 
As críticas feitas à psiquiatria biológica não devem impedir de reconhecer que ela trouxe a desculpabilização de pacientes e familiares por suas psicoses, seus transtornos alimentares, anorexia, autismo e esquizofrenia. Sirva como exemplo as famílias de filhos esquizofrênicos que suportam financeiramente as pesquisas de esquizofrenia que usam neuroimagem, isto é, uma abordagem cerebral da doença (Dumit 2004). Para o paciente e seus familiares, é mais fácil aceitar, por exemplo, o diagnóstico de transtorno bipolar do que o de psicose maníaco-depressiva, pois no transtorno bipolar são enfatizados os aspectos biológicos e cerebrais mais do que os psicológicos e os psicodinâmicos que impunham uma marca identitária. O indivíduo não é mais psicótico maníaco-depressivo, mas tem transtorno bipolar.

A doença mental como critério identitário aplica-se mais a modelos psicológicos (ou psicanalíticos) e mentalistas do que a modelos fisicalistas/ cerebralistas oriundos da psiquiatria biológica ou das neurociências. Não é o mesmo afirmar "há algo errado comigo" do que "há algo errado com meu cérebro". Ao passo que a doença mental diz respeito à identidade, o transtorno cerebral diz respeito ao corpo (cérebro). Se for um problema do cérebro, então o indivíduo não é culpado e, sobretudo, ele não é essa doença, ela não define a sua identidade. Em face da psicologização da doença mental, o cerebralismo pressupõe uma dessubjetivação. Ora, no caso dos movimentos da neurodiversidade acontece exatamente o contrário: o cerebralismo constitui uma marca identitária, uma identidade naturalizada - o indivíduo é autista (e não tem autismo) — não pelo autismo ser uma doença mental, mas precisamente porque é uma "conexão atípica" (atypical wiring) do cérebro. Para esses grupos, autismo, transtorno bipolar, transtorno de déficit de atenção, entre outros, constituem marcas identitárias não por serem doenças mentais, mas por serem transtornos cerebrais, isto é, identidades biológicas, bioidentidades ou, mais precisamente, neuroidentidades, que são a base da formação de neurossociabilidades e neurocomunidades. Os movimentos da neurodiversidade, especificamente a cultura autista, constituem exemplos de formas de subjetivação cerebrais, de formação de neuroidentidades e tipos de sociabilidade e comunidade, as neurossociabilidades, tomando o cérebro como referência, como veremos adiante.

Nesse contexto de cerebralismo da identidade autista, não devemos nos esquecer que ainda não existe consenso acerca da etiologia do autismo. Embora psiquiatras, biológicos e neurocientistas venham procurando nos últimos anos o "endereço cerebral" (brain address) do transtorno (Wickelgren 2005:1856) e considerem o autismo um transtorno biológico, mais especificamente cerebral (Fombonne 2003; Freeman \& Cronin 2002; Wing 1997) levando alguns a percebê-lo como um caso extremo do cérebro masculino 
normal (Baron-Cohen 2002), não existe consenso nem sobre a etiologia, ${ }^{13}$ nem sobre a metodologia de intervenção clínica (Feinberg \& Vacca 2000:131; Newschaffer \& Curran 2003). Para os autistas, por sua vez, não existe dúvida, eles afirmam categoricamente o cerebralismo do transtorno.

Para Temple Grandin, talvez a autista mais famosa, "o autismo é um transtorno neurológico. Uma criança nasce com isso. Isto é causado por um desenvolvimento imaturo do cérebro - isso já foi verificado em estudos de autópsias cerebrais - e não por má criação ou pelo ambiente" (apud Blume 1997). Ela também fez elogios entusiásticos na contracapa do livro de Edward Dolnick, Madness on the couch. Blaming the victim in the heyday of psychoanalysis, que constitui uma crítica feroz às explicações psicanalíticas do transtorno. A posição da comunidade autista é clara: "autismo não é nem uma deficiência física (corporal), nem uma doença mental: é uma deficiência neurológica" (Dekker 2006). A cerebralidade do transtorno é assumida como um fato pela comunidade autista, nunca é colocada em questão, aparecendo já no termo (neuro)diversidade. Nesse aspecto, eles coincidem com as associações de pais de autistas, os quais também privilegiam a etiologia cerebral e genética do transtorno.

A divergência está mais para se considerar o autismo como um transtorno cerebral ou uma diferença na wiring cerebral. Todavia, acredito que essa preferência pelas explicações cerebrais não se reduza à aversão à psicanálise e à cultura psicológica presentes em ambos os grupos. Deve ser compreendida antes no contexto da neurocultura e do paradigma do sujeito cerebral e no privilégio de formas de subjetivação cerebrais, como veremos a seguir. Harvey Blume (1997) faz uma constatação semelhante ao afirmar que o "autismo não é praticamente a única — nem de longe a principal razão para a atual escalada da neurologia. O contrário pode estar mais próximo da verdade: a escalada da neurologia sustenta o motivo do aumento da atenção que tem sido dada ao autismo".

\section{Sujeito cerebral e neurocultura}

O contexto geral que permite compreender o surgimento e a difusão dos movimentos de neurodiversidade é aquele da cultura somática ou da biossociabilidade, ${ }^{14}$ mais especificamente, da neurocultura e do sujeito cerebral. Entendo por biossociabilidade uma forma de sociabilidade apolítica constituída por grupos de interesses privados, não mais reunidos segundo critérios de agrupamento tradicional, como raça, classe, estamento, orientação política, como acontecia na biopolítica clássica oitocentista analisada por Foucault 
(1976, 1997, 1999), mas sim segundo critérios de saúde, performances corporais, doenças específicas, longevidade, entre outros. Na biossociabilidade criam-se novos critérios de mérito e reconhecimento, novos valores com base em regras higiênicas, regimes de ocupação de tempo, criação de modelos ideais de sujeito baseados no desempenho físico. As ações individuais passam a ser dirigidas com o objetivo de se obterem melhor forma física, mais longevidade e/ou o prolongamento da juventude.

Na biossociabilidade, a vida psíquica é descrita segundo predicados corporais. Todo um vocabulário fisicalista-reducionista é utilizado na descrição de crenças, sentimentos, desejos, volições. Os atos psicológicos têm sua origem em causas físicas e as aspirações morais do indivíduo são medidas segundo performances corporais. Como conseqüência, concepções psicológicas e internalistas de pessoa são deslocadas para a exterioridade, dando lugar à constituição de identidades somáticas, as bioidentidades (Costa 2004; Ortega 2008). Esta acontece mediante toda uma série de recursos reflexivos e de práticas de si, a bioascese, a qual reproduz no foco subjetivo as regras da biossociabilidade, enfatizando-se os procedimentos de cuidados corporais, médicos, higiênicos e estéticos na construção de identidades pessoais. A distinção entre corpo e self tornou-se obsoleta nas bioidentidades. O físico transformou-se em um signo cardinal do self, de uma maneira não mais conseguida por meio de acessórios, tais como moda e cosméticos. As práticas bioascéticas fundem corpo e mente na formação da bioidentidade somática, produzindo um eu que é indissociável do trabalho sobre o corpo, o que torna obsoletas antigas dicotomias, tais como corpo-alma, interioridade-exterioridade, mente-cérebro.

Nesse processo de descrição da individualidade e da subjetividade em termos corporais, o cérebro ocupa um lugar privilegiado. O espetacular progresso das neurociências, o intenso processo de popularização pela mídia de imagens, as informações que associam a atividade cerebral a praticamente todos os aspectos da vida e certas características estruturais da sociedade atual vêm produzindo, no imaginário social, uma crescente percepção do cérebro como detentor das propriedades e autor das ações que definem o que é ser alguém. Nas últimas décadas, precipitaram-se as condições para o surgimento dessa nova figura antropológica. Entre elas, o fortalecimento do cientificismo; o apagamento da política e das práticas sociais que faziam apelo ao sujeito como autor de sua existência individual e coletiva; a emergência de uma cultura da objetividade que valoriza a imagem em detrimento da palavra e da interpretação; o mencionado deslocamento das regras de socialização fundadas na interioridade sentimental em direção a uma cultura da subjetividade somática; a explosão da tecnociência, das biotecnologias 
e do consumo intensivo de produtos e serviços voltados para a otimização do desempenho biológico como correlato das práticas de si, e assim por diante. Como resultado, o cérebro responde cada vez mais por tudo aquilo que outrora nos acostumamos a atribuir à pessoa, ao indivíduo, ao sujeito. Inteiro ou em partes, o cérebro surgiu como o único órgão verdadeiramente indispensável para a existência do self e para definir a individualidade.

Crenças, desejos e comportamentos são freqüentemente descritos em um vocabulário cerebral ou neuroquímico, tal como encontramos no romance de Jonathan Franzen - The corrections - que pode ser lido como uma crítica à cultura terapêutica e ao cerebralismo das relações humanas. Nikolas Rose (2003) define esse processo usando o termo "self neuroquímico" (neurochemical self), isto é, a formação neuroquímica da pessoa.

O termo "sujeito cerebral" (Vidal 2005; Ortega \& Vidal 2006, 2007; Ehrenberg 2004) resume adequadamente a redução da pessoa humana ao cérebro: a crença de que o cérebro é a parte do corpo necessária para sermos nós mesmos, no qual se encontra a essência do ser humano, ou seja, a identidade pessoal entendida como identidade cerebral. Indagar acerca do sujeito cerebral é tentar responder à pergunta de por que a afirmação "eu sou meu cérebro" tornou-se auto-evidente. O sujeito cerebral constitui uma figura antropológica privilegiada na biossociabilidade. Vários historiadores das neurociências ressaltam que o destaque dos conhecimentos neurocientíficos e das descrições subjetivas segundo o vocabulário dos saberes cerebrais, isto é, o cerebralismo da identidade pessoal, não ocupa um lugar tão realçado na nossa cultura devido ao progresso alucinado das tecnologias neurocientíficas (mais especificamente, de imageamento cerebral), ou mesmo à importância do cérebro na localização de processos cognitivos e emocionais (Hagner \& Borck 2001). O cerebralismo da subjetividade deve ser entendido no contexto da cultura das bioidentidades, na qual o chamado "programa forte" das neurociências (Ehrenberg 2004) - aquele que, fundindo neurociência e psiquiatria, identifica conhecimento de si e conhecimento do cérebro, mente e cérebro, transformando o cérebro em ator social - possui cada vez maior aceitação.

O sujeito cerebral dá lugar à aparição de práticas de si cerebrais, as neuroasceses, isto é, discursos e práticas de como agir sobre o cérebro para maximizar a sua performance, os quais levam à formação do que vou chamar de neurossociabilidades e neuroidentidades. As neuroasceses incluem toda uma literatura de best-sellers de auto-ajuda cerebral, a qual oferece desde programas de exercícios para aumentar a performance e o poder cerebral, prevenindo a decadência mental e combatendo demências, até a manipulação do cérebro para promover estados alterados da consciência capazes de 
conectá-lo com as forças do universo e com uma inteligência superior, a Mente Cósmica ou Divina (Ortega 2006). Numerosas empresas estão investindo nos neuronegócios e desenvolvendo programas de computador e outros produtos neuroascéticos para garantir o aprimoramento do cérebro. Algumas empresas oferecem um "brain gym" completo para treinar os diferentes sistemas cognitivos: visão, controle executivo, equilíbrio, mobilidade. As neurotecnologias apresentam-se como um ramo extremamente promissor (Lynch 2004).

O objetivo é a formação de "selves objetivos", de "autoconstituição objetiva" (objective self-fashioning), usando a expressão de Joseph Dumit (2004) para se referir ao processo de formação de um self objetivo, ou seja, uma categoria de pessoa desenvolvida mediante conhecimento expert. É um processo duplo: por um lado, as práticas da ciência da medicina e da tecnologia formam selves mediante a experimentação científica, os exercícios de taxonomia médica etc., isto é, produzem "fatos" que definem objetivamente quem somos; por outro, os indivíduos formam seus próprios modelos de self a partir dos fatos científicos. A noção de self objetivo remete a uma compreensão da subjetividade que tem como ponto de partida discursos técnicos, científicos e médicos sobre a objetividade, ou seja, exprime um oximoro, ao juntar palavras de significados opostos, uma subjetividade objetivada, uma forma de self, na qual a perspectiva fenomenológica e subjetiva da primeira pessoa é reduzida à perspectiva em terceira pessoa exprimida mediante as tecnologias médicas e os discursos e as práticas objetivantes.

Os indivíduos constituem a si mesmos objetivamente a partir da incorporação em suas vidas de "fatos" sobre si mesmos - seus corpos, mentes, cérebros. São "fatos objetivos" veiculados pela mídia que são incorporados nas descrições de nós mesmos. Os jornais e as revistas de divulgação científica, a televisão e o cinema difundem continuamente imagens que insistem na associação entre o cérebro e a mente, a mente no cérebro. A mídia capitaliza precisamente a potente familiaridade e a transparência das imagens. O risco é grande, os limites entre as imagens entendidas como representações de correlações ou de relações causais entre estados mentais e estruturas cerebrais é ultrapassado com freqüência, sendo essas imagens interpretadas como registros objetivos de estados emocionais e mentais. Quando uma cultura como a nossa equaliza o estatuto cerebral com o estatuto mental e com a própria personalidade, então as imagens se tornam prejudiciais ao difundirem visões reducionistas e objetivizadas da pessoa humana, os "selves objetivos", com conseqüências severas em diversas esferas socioculturais e clínicas.

Na sociedade contemporânea, é preciso levar em consideração diferentes fatores na formação de "selves objetivos", tais como o papel desem- 
penhado atualmente pela mídia, as tecnologias de visualização médica, o programa "forte" das neurociências, a indústria de psicofármacos, entre outros. ${ }^{15}$ Tampouco podemos esquecer o papel fundamental da cultura somática, na qual, como foi ressaltado, as formas de subjetivação corporais ocupam cada vez mais o lugar de formas internalistas e intimistas de construção e descrição de si, próprias de culturas mais psicológicas. Isto faz uma grande diferença, criando um contexto cultural propício para as formas de subjetivação favoráveis e para a constituição de neuroidentidades, fornecendo à neurossociabilidade (que inclui os movimentos de neurodiversidade) uma visibilidade crescente.

Na cultura somática da biossociabilidade, a neurossociabilidade está ocupando um espaço cada vez maior. Encontramos, por um lado, todo um mercado crescente de produtos, entre os quais se incluem best-sellers de auto-ajuda cerebral, softwares e programas de brain-fitness para o computador que constituem verdadeiras "academias para o cérebro" (brain gyms), vitaminas e todo tipo de suportes alimentares para aprimorar a performance cerebral (Brownlee 2006a, 2006b, CBS 2006; Singer 2005; Ortega 2006). Por outro lado, o sujeito cerebral vem se tornando um critério biossocial de agrupamento, como podemos constatar no surgimento, entre outros, de:

a) Grupos que se reúnem para testar as performances cerebrais, como se depreende da existência de "clubes do cérebro", "campeonatos mundiais de memória" e "olimpíadas de esportes da mente", promovidos pelo empresário Tony Buzan, criador dos mapas mentais e autor de numerosos best-sellers de auto-ajuda cerebral. ${ }^{16}$ Neles, os cérebros são submetidos a verdadeiras competições mentais, que incluem desde jogos mentais clássicos a exercícios para medir pensamento criativo, velocidade de leitura ou cálculos mentais e de memória.

b) Neurocomunidades como a Braingle Community, ${ }^{17}$ orientada para um público adolescente, e que abrangem fóruns de discussão, "talk boxes" que permitem conversas privadas, e serviço de "live chat". Os neurousuários podem fazer observações sobre assuntos cerebrais, comentar os novos jogos, puzzles e "Brain Teasers", visando promover a atividade cerebral. Ao mesmo tempo, a comunidade tem acesso a todo um "mercado" cerebral. Uma indústria "neuro" está surgindo para compras on-line, e ela não só inclui livros, jogos, videogames, mas também camisetas, bonés, canecas, mousepads, neurocalendários e outros artigos que ajudam a delinear a identidade coletiva das novas neurocomunidades. Nesse sentido, os recursos para crianças são descomunais, como podemos constatar ao se digitar a expressão "neuroscience for kids" em qualquer mecanismo de busca na internet.

c) Grupos de apoio para portadores de diferentes doenças e transtornos neurodegenerativos e seus familiares, tais como doença de Alzheimer, 
esquizofrenia, doença de Parkinson, esclerose múltipla, Transtorno de Déficit de Atenção e Hiperatividade (TDAH), demência Frontotemporal (Frontotemporal Dementia - FTD), Doença de Huntington (Hungtinton Disease), entre outros. As funções e os objetivos desses grupos são diferentes, atendendo também às especificidades das diversas doenças e dos transtornos, contemplando atividades que vão desde palestras e troca de informação e experiências até exercícios, serviços religiosos ou ajuda psicológica. Intervenções psicossociais variadas e troca de experiências podem se dar em encontros regulares ou por meios virtuais, como Internet, com o uso de videoconferências, comunidades no yahoo, orkut, entre outros. ${ }^{18}$ As associações de pais de autistas e grupos pró-cura inserem-se neste contexto. Os grupos da neurodiversidade têm também elementos em comum com esses grupos no nível de organização e de sociabilidade, embora divirjam em outros aspectos, especialmente em relação à ideologia pró-cura.

A noção de neurossociabilidade permite compreender como o sujeito cerebral se torna um critério de agrupamento, isto é, como dá lugar à formação de diversos grupos, sejam eles de portadores de alguma doença neurodegenerativa e seus familiares, ou de indivíduos que se reúnem para testar a sua performance cerebral, ou de grupos de autistas que usam o critério cerebral para reclamar um acesso à cidadania que o modelo biomédico lhes tinha negado. Um modelo de "subjetivade-objetiva", que surgiu a partir de uma ideologia reducionista e solipsista da compreensão da subjetividade e da vida social, serve paradoxalmente para criar novas formas de subjetividade e de sociabilidade que têm no cérebro a sua âncora.

\section{Neuro-diversidade e neurociências}

Acredito que esta descrição do sujeito cerebral e da neurocultura constitui o pano de fundo para compreender a cerebralidade que está na base dos movimentos da neurodiversidade. Para esses grupos, o cérebro vem se tornando um critério biossocial de agrupamento fundamental. É nesse contexto que podemos entender a própria noção de (neuro)diversidade. Se pararmos para pensar, a junção destes dois termos, "neuro" e "diversidade", não é auto-evidente. A diferença e a singularidade são colocadas do lado cerebral. Trata-se, como vimos, de uma naturalização da identidade. Mas como pode ser o cérebro o lugar do diverso, da diferença? - podemos perguntar.

As pesquisas neurocientíficas - por exemplo, na área da psiquiatria biológica (por ser esta a mais próxima do autismo) — não se caracterizam precisamente pela busca de regularidades e constantes neuroanatômicas e 
neurofisiológicas que permitem distinguir um cérebro autista, ou deprimido, ou esquizofrênico de um cérebro normal, como mostram os estudos com neuroimagem? Não se trata de localizar no cérebro as regiões responsáveis pelos mais diversos estados mentais, normais ou patológicos? Ou seja, não se considera o cérebro o lugar da identidade, das constâncias, das regularidades? Nesse caso, não existiriam termos mais adequados para se pensar a diversidade do que psico-diversidade ou mind-diversidade? Entenda-se psico não em referência a qualquer teoria psicológica ou psicanalítica, dada a aversão dos autistas a elas, mas no sentido de "mental"; porém, soa estranho em português o termo mente-diversidade. Talvez pudéssemos pensar em "diversidade mental" em oposição à "diversidade neural" ou à neurodiversidade? Afinal, é do lado do mental que se torna possível imaginar o diverso, o múltiplo, o singular, tantas formas de vida que a imaginação, a fantasia e a criatividade consigam pensar. Do lado corporal (cerebral), o repertório de possibilidades é finito. Tomo como exemplo a seguir o caso das modificações corporais que tenho analisado em outro lugar (Ortega 2008).

Tatuagens, piercings, cutting, brainding, implantes subcutâneos, entre outros, constituem tentativas de dar uma localização específica e corporal à identidade subjetiva. A autenticidade, a realidade, a identidade e a autonomia pessoal são colocadas no lado corporal. O desarraigamento social e a ausência de vínculos simbólicos e de rituais coletivos que são próprios de nossas sociedades contemporâneas - salientados por diversos sociólogos, filósofos e historiadores - conduzem o indivíduo a se retrair em si e a fazer de seu corpo um universo em miniatura, uma verdade de si e um sentimento de realidade que a sociedade não consegue mais lhe fornecer. ${ }^{19} \mathrm{~A}$ modificação corporal responde a um déficit identitário, constitui uma suplência de identidade, um tipo de assinatura de si através da qual o indivíduo se afirma na identidade escolhida, que difere daquelas que lhe são atribuídas pelo olhar do outro.

No entanto, o repertório que o indivíduo dispõe para criar uma identidade corporal, naturalizada, é finito, dado pelos próprios limites de seu corpo. Daí surgirem modificações cada vez mais radicais, que incluem a amputação de diversos membros corporais, como no caso da apotemnophilia, ou o desejo de ter várias partes do corpo amputadas. Chegará um momento em que a superfície (ou o interior) do corpo estará completamente ocupada por piercings e demais marcas corporais identitárias. Ao repertório limitado de identidades corporais opõe-se a riqueza infinita da identidade psicológica ou mental em função da própria imaterialidade do mental. Isto sem mencionar o engodo psíquico que supõe localizar a identidade pessoal no corpo. Se o que somos está exposto ao olhar do outro, somos privados da capacidade de fingir, de dissimular, de esconder os sentimentos, as intenções, os segredos. 
Somos vulneráveis ao olhar do outro, porém, ao mesmo tempo, precisamos de seu olhar, para sermos percebidos, senão não existimos.

O mesmo se aplica à busca da identidade e da diversidade do lado cerebral. Em primeiro lugar, vale a pena fazer uma ressalva sobre o "boom" recente de teorias, práticas e produtos que exploram a "neuroplasticidade", recorrente da descoberta da neurogênese em adultos..$^{20}$ Embora a plasticidade cerebral desloque para o pólo cerebral características como multiplicidade, criatividade e singularidade ${ }_{1}^{21}$ não acredito, todavia, que a plasticidade cerebral leve a equiparar a potencialidade de possibilidades do mental com o cerebral. Ela não substitui a potencialidade de expressões subjetivas do mental. No fundo, os mais diversos estudos realizados com neuroimagem vêm corroborar este raciocínio. A complexidade e a riqueza das experiências mentais não são reduzíveis à simplicidade e à pobreza das redes neurais ou das medidas neuroquímicas.

Para elucidar este ponto, tomo como exemplo os trabalhos de Newberg e D'Aquili. Escaneando o cérebro de oito budistas americanos praticantes de meditação tibetana e de três freiras franciscanas em oração contemplativa, os autores pretendem mostrar que em ambos os grupos se observa aumento de atividade neural no córtex pré-frontal e diminuição de atividade no lobo parietal posterior superior (D'Aquili \& Newberg 1999; Horgan 2003). Todavia, caberia perguntar se esses dados, procedentes do pólo cerebral, fornecem alguma informação importante sobre o pólo mental, para além do fato óbvio (se não quisermos reeditar alguma versão do dualismo clássico) de que toda a experiência mental (inclusive as espirituais) possui correlatos cerebrais. ${ }^{22}$

Podemos identificar a experiência espiritual de vazio, o Nirvana dos budistas, com o sentimento de comunhão com o Deus das freiras? Seria ingênuo se acreditássemos na identidade das duas. Obviamente, trata-se de duas experiências subjetivas completamente diferentes, correspondentes a duas visões de mundo, a concepções teológicas e espirituais diversas e a contextos socioculturais distintos, ainda que possuam o mesmo correlato neural. A riqueza e a diversidade do pólo mental (espiritual) perdem-se na pretensa redução ao pólo material, cerebral. Trata-se de uma tradução grosseira, simplificadora e ingênua.

Parafraseando o título do livro de William James, as "variedades da experiência religiosa" não são traduzíveis à monotonia e à uniformidade de seus correlatos neurais. Um único mecanismo neural não pode nem poderá dar conta da totalidade e da diversidade das experiências espirituais. Da mesma maneira, se pudessem ser delimitados os correlatos neurais da depressão, isto indicaria alguma coisa acerca da experiência singular do sujeito deprimido? Os cérebros deprimidos podem ser iguais, os sujeitos 
deprimidos com certeza não o são. Acaso é a mesma coisa a experiência do sujeito que está deprimido porque foi abandonado pela mulher, ou porque perdeu o emprego, ou se sente atingido pela violência e pela desigualdade da sociedade em que vive? Sem dúvida, não! Mas se o correlato cerebral for o mesmo? Novamente encontramos a diversidade, a multiplicidade e a heterogeneidade do lado mental oposta à simplicidade, à homogeneidade e à uniformidade do lado cerebral. Ou vamos afirmar que é o mesmo cantar funk, música sacra ou A Internacional, ainda que do lado cerebral a mesma região esteja sendo ativada?

Assim, caberia perguntar se, ao apostar no pólo cerebral para defender a diversidade de formas de vida, não estaria o movimento da neurodiversidade se afastando da riqueza do mundo mental, no qual o que aproxima e distancia os indivíduos são as visões de mundo, os ideais e as esperanças, compartilhadas ou não? Não estariam apostando em uma diversidade que no fundo é uma forma de homogeneidade, situando a própria diferença em uma identidade naturalizada, marcada no cérebro e, como conseqüência, de uma política da identidade? No fundo, o movimento posiciona na área do "neuro" o que se costumava posicionar na área do mental e do social. Esse deslocamento deve ser compreendido no contexto da ideologia do sujeito cerebral, no qual o cérebro responde por tudo o que outrora costumávamos atribuir à pessoa, ao indivíduo, ao sujeito. O cérebro vem se tornando, na neurocultura, o ator social privilegiado. Com isso, obviamente não estou defendendo uma visão que reative certo dualismo e dicotomias tradicionais, privilegiando algum tipo de mentalismo como alternativa ao materialismo cerebralista do sujeito cerebral. Mentalismo idealista ou materialismo subjetivista são visões redutivas e simplificadoras da experiência humana. ${ }^{23}$

O movimento da neurodiversidade acolhe o paradigma construtivista imperante nos "estudos sobre deficiência" (disability studies), segundo o qual deficiência e doença não são fatos biológicos, mas construções socioculturais que visam regulamentar os corpos e os cérebros (Davis 1995; Diniz 2007) uma posição que é compartilhada pela chamada "psiquiatria pós-moderna", crítica da substituição da compreensão sociocultural, política e religiosa da doença mental pelo paradigma psicopatológico e neurocientífico. Ela descarta qualquer dimensão cientificista da psiquiatria que procure correlações entre transtornos mentais e lesões cerebrais (Brendel 2006). Resulta paradoxal que, exatamente nesse modelo construtivista, a neurodiversidade organize a identidade em torno de algo tão pouco construído e tão biológico como é o cérebro. O cerebralismo da identidade e da sociabilidade representa uma posição materialista que envolve uma naturalização extrema, ao contrário da construção. Para o movimento da neurodiversidade, o cérebro não é 
uma construção social. Coexistem no movimento o impulso construtivista e a naturalização identitária. Novamente se coloca o direito à diferença a par com os predicados biológicos de uma identidade marcada no cérebro.

\section{Rumo a uma política identitária}

Com isso, entramos no último ponto que gostaríamos de abordar neste texto e que constitui o maior desafio para os movimentos da neurodiversidade: a tentação da "política identitária". Ao colocar o direito à diferença do lado biológico (cerebral), o movimento da neurodiversidade corre o risco de cair em uma política identitária calcada em predicados naturais e que conduz a uma redução da pluralidade à identidade, homogeneizando as diferenças e suprimindo a singularidade dentro do próprio movimento. Sirva a advertência que Agnes Heller fez acerca do movimento feminista radical quanto ao perigo da homogeneização do grupo qua diferença: "Os que falam em nome das mulheres se colocam no lugar de todas as mulheres, da metade da humanidade, enquanto as mulheres podem ter, e de fato têm, aspirações totalmente diferentes e imagens de si completamente divergentes; possivelmente recusam a imagem prescrita por feministas radicais" (Heller 1995; Feher \& Heller 1994). Para dizer a verdade, nos debates entre os grupos pró-cura e o movimento autista anticura, reconhecemos no tom, nos argumentos e na pretensão de falar em nome de todos os autistas, a descrição que Heller faz dos movimentos biopolíticos. "No discurso biopolítico", escreve a filósofa húngara, "os grupos autodefinidos determinam também as condições para as contribuições dos outros. Um discurso que 'desmascara' outros discursos, que trata com desconfiança o diferente, não é em realidade público. Todas as raças e ambos os sexos encontram aqui sua própria verdade; e quanto mais poderosos são seus lobbys mais enfaticamente tentam proclamar sua verdade como incontestável e absoluta. As opiniões divergentes não são aceitas, e as opiniões contrárias não são ouvidas" (Heller 1995).

Alguns teóricos dos "estudos sobre deficiência" vêm chamando a atenção para o perigo de que a valorização de ser deficiente esteja relacionada com a comparação e a hostilidade com os não-deficientes (Swain \& Cameron 1999) e, em face de uma idéia de comunidade fechada, calcada em uma política identitária reducionista, propõem criar comunidades mais abertas e democráticas (Corker 1999). Essa autocrítica foi feita recentemente no interior do próprio movimento da neurodiversidade. Jim Sinclair (2005) recriminou o preconceito de certos autistas contra os neurotípicos. E a própria Judy Singer, que impulsionou e deu grande visibilidade ao mo- 
vimento, reconheceu há pouco tempo que ele está caminhando para o "lado escuro" da política identitária, com "sua eterna vitimização, infantilidade e demanda por amor incondicional e aceitação sem uma auto-reflexão adulta concomitante, um autocriticismo, uma medida de estoicismo e desejo de ver luz e escuridão em si próprio, assim como no 'Outro'". ${ }^{24}$

Singer faz ao mesmo tempo uma outra crítica, fundamental para se compreender o papel da ontologia do sujeito cerebral e da neurocultura nos movimentos da neurodiversidade. O cerebralismo da identidade é assumido, como vimos, sem questionamento pelo movimento. A ativista australiana ressalta que a chamada revolução neurocientífica não traz apenas vantagens e que os autistas precisam ter uma visão mais equilibrada sobre o impacto das neurociências na vida e no destino das pessoas, autistas ou não. Estamos dispostos a pagar o preço exigido por nos definirmos cerebralmente? O sujeito cerebral não sugere apenas a idéia de conexões cerebrais diferentes e atípicas, que não devem ser "patologizadas" nem normalizadas, mas sim ele implica formas de subjetivação, isto é, relações consigo mesmo e com os outros enquanto sujeitos cerebrais. ${ }^{25}$

Este fato remete a visões reducionistas e empobrecidas da vida subjetiva e relacional, segundo as quais o cérebro responde por tudo o que outrora costumávamos atribuir ao indivíduo, ao ambiente e à sociedade, com conseqüências severas em diversas esferas socioculturais e clínicas. Entre elas, estão o perigo das políticas identitárias reducionistas e as explicações da depressão e de outros transtornos e doenças mentais em termos exclusivamente cerebrais, fornecidas pela psiquiatria biológica aliada à indústria farmacêutica, ignorando-se os fatores ambientais e sociais. É preciso saber se queremos pagar esse preço.

\section{Considerações finais}

Tentei neste artigo mostrar alguns dos desafios que se apresentam aos movimentos da neurodiversidade. Meu objetivo principal não era tomar partido a favor ou contra os grupos pró ou anticura, pois acredito que ambos têm as suas razões. Os primeiros, ao criticarem as políticas identitárias agressivas praticadas por ativistas radicais do movimento autista e que se propõem a falar em nome de todos os autistas. ${ }^{26}$ Os ativistas autistas são freqüentemente autistas de "alto funcionamento", em geral Aspergers, que se outorgam o direito de se manifestarem em nome de todos os autistas, o que causa irritação nos pais de filhos autistas de "baixo funcionamento", com grave atraso físico e mental. Obviamente seria hipocrisia subsumir todas as formas 
de autismo ao "alto funcionamento", para depois dizer que autismo é um estilo de vida. O movimento da neurodiversidade é minoritário no espectro total do autismo. Muitos autistas não possuem nem a capacidade cognitiva de falar o que pensam ou sentem, quanto mais de se organizarem política e comunitariamente. Os ativistas autistas, por sua vez, têm suas razões de temer políticas igualmente agressivas que incluam testes genéticos capazes de possibilitar o aborto de fetos autistas, bem como a imposição de ideais e padrões de normalidade cerebral que redundem em terapias e na obrigação de serem "curados".

Se o autismo é um espectro, não pode ser tratado como uma entidade nosológica fechada. Seu alcance e seus limites exigem uma constante negociação pública. Qualquer decisão acerca de um ponto de corte ao longo do espectro do transtorno autista será sempre arbitrária, resultado de interesses e lobbys de determinados grupos. Não existem até hoje critérios objetivos que permitam estabelecer um ponto de corte no espectro, a partir do qual os indivíduos possuiriam ou não uma "teoria da mente" (Baron-Cohen 1995; Frith 1991) ou as "condições de personalidade" (selfhood) (Glannon 2007) necessárias para que sejam tomadas decisões objetivas acerca da imposição de terapias ou testes genéticos e para a atribuição de autonomia e responsabilidade por suas ações aos indivíduos diagnosticados como autistas.

Queria apenas apresentar esses impasses e embates no seio da neurocultura, no qual o movimento da neurodiversidade é uma manifestação, e mostrar como uma ideologia solipsista, reducionista e cientificista - como é o sujeito cerebral - pode servir de base para a formação de identidade e de redes de sociabilidade e comunidade. Poderíamos parafrasear Foucault e afirmar que todo dispositivo de saber-poder é um mecanismo de assujeitamento, mas ao mesmo tempo abre a possibilidade da resistência. O desafio do movimento da neurodiversidade oscila entre a aposta em políticas identitárias que são meros epifenômenos do sujeito cerebral ou procurar alternativas para esta ideologia simplificadora da vida subjetiva e relacional. 


\section{Notas}

${ }^{1}$ http://en.wikipedia.org/wiki/Neurodiversity (acessado em 01/12/2006).O mais famoso é http://www.neurodiversity.com (acessado em 01/12/2006).

${ }^{2}$ Ver a introdução de "Autistic Pride Day" em Wikipedia: http://en.wikipedia. org/wiki/Autistic_Pride_Day (acessado em 16/06/2007).

${ }^{3}$ Resulta sintomático que, em um especial dedicado ao autismo, a revista EPOCA tenha apresentado apenas a visão pró-cura e pró-terapia cognitiva do transtorno. Ver Nogueira, 2007.

${ }^{4}$ Para entender o debate e as posições em jogo, ver o excelente verbete "Autism rights movement" em Wikipedia, op.cit.

5 "Curebie" é um termo criado pela comunidade autista para descrever e criticar aqueles que pretendem desesperadamente curar o autismo. É um termo de difícil tradução, que poderia ser vertido como "obcecado pela cura" (Weintraub s/d). Ver http://www. urbandictionary.com/define.php?term=curebie (acessado em 30/09/2007).

${ }^{6}$ Esta posição foi consensual na psicanálise americana entre os anos de 1940 e 1960, identificada fundamentalmente com as figuras de Leo Kanner e Bruno Bettelheim. Sirva como exemplo a seguinte frase lapidar de Bettelheim no seu famoso A fortaleza vazia (The empty fortress): "Eu mantenho minha crença de que o fator precipitante no autismo infantil é o desejo dos pais de que seu filho não deveria existir" (Bettelheim 1967:125). Ver também Pollack 1997.

${ }^{7}$ Uma lista de artigos de Michelle Dawson encontra-se em http://neurodiversity. com/dawson.html (acessado em 1/04/2007).

${ }^{8}$ Sobre o caso Auton vs. British Columbia, ver a série de matérias e artigos em: http://neurodiversity.com/auton.html (acessado em 1/04/2007). Um bom resumo do caso oferece a seguinte entrada de Wikipedia: http://en.wikipedia.org/wiki/Auton_\%28Guardian_ad_litem_of\%29_v._British_Columbia_\%28Attorney_General\%29 (acessado em 10/06/2007) . Ver também Baker 2006; Harmon 2004c; Feinberg \& Vacca 2000; Newschaffer \& Curran 2003.

${ }^{9}$ O DSM (Diagnostic and Statistical Manual of Mental Disorders) da Associação Psiquiátrica Americana é o sistema diagnóstico mais utilizado nos Estados Unidos, encontrando-se atualmente na $4^{\mathrm{a}}$. ediçãa (1994). Esse sistema é consistente com a CID (Classificação Internacional das Doenças, da Organização Mundial de Saúde OMS), que se encontra na $10^{\mathrm{a}}$. edição.

10 "Os pais são retratados como controladores enlouquecidos, egoístas e perfeccionistas (espectros das 'mães geladeiras!') e os profissionais que devotaram suas 
vidas para ajudar nossos filhos são descritos como frios manipuladores e abusadores infantis", escreve Kit Weintraub (2005) em relação aos movimentos de autistas.

${ }^{11} \mathrm{http}: / /$ isnt.autistics.org

${ }^{12}$ Sirva como exemplo o depoimento relatado no artigo de Harvey Blume (1997) acerca de uma mulher com autismo: "Depois de passar '... sua adolescência em um estado clínico suicida-depressivo devido ao abuso sofrido e ao sentimento de ser uma fracassada ou insana por ser diferente', ela encontrou sua opinião 'apenas reforçada pelo psicoterapeuta, ao qual fui encaminhada, que decidiu que todos os meus problemas tinham que ser o resultado de uma 'repressão sexual'. Ela se declara orgulhosa de si mesma por ter 'ido embora após seis sessões' e concluí que ter sido diagnosticada como autista 'foi a melhor coisa que já me aconteceu'".

${ }^{13}$ A comunidade científica defende atualmente os seguintes fatores causais na etiologia do autismo: predisposição genética, explicações neuroquímicas, explicações baseadas em vacinas, toxinas ambientais e teorias nutricionais (Feinberg \& Vacca 2000:131).

${ }^{14}$ Uso o termo em sentido mais amplo que o de Paul Rabinow (1992), que o utiliza para analisar as implicações socioculturais e políticas da genética e do projeto Genoma. Para o antropólogo americano, a genética deixará de ser apenas uma metáfora biológica para descrever o social, levando à formação de identidades e práticas sociais. No texto, uso o conceito de Rabinow, sublinhando o elemento dos processos de subjetivação, mas sem limitá-lo especificamente à genética, estendendo o uso a diferentes formas de subjetividade biológica ou somática presentes nas sociedades contemporâneas, incluindo o sujeito cerebral. O termo é usado para definir uma forma de sociabilidade contemporânea, na qual a vida psíquica é descrita segundo predicados corporais, como se depreende do vocabulário fisicalista utilizado na descrição de crenças e sentimentos, levando à constituição de identidades somáticas que deslocam concepções psicológicas e internalistas de pessoa.

${ }^{15}$ A bibliografia sobre o tema é imensa. Ver, entre outros, Ackerman 2006; Dumit 2003, 2004; Ehrenberg 2004; Illes 2006; Healy 2002; Joyce 2005; Rodriguez 2006; Rose 2005, 2006; Valenstein 1998; Russo \& Venâncio 2006; Russo 2005; Russo \& Henning 1999.

${ }^{16}$ Ver, www.buzanworld.com/biography.html (acessado em 3/06/2006); Verbete "Tony Buzan" in Wikipedia, http://en.wikipedia.org/wiki/Tony_Buzan (acessado em 3/06/2006).

${ }^{17}$ http://www.braingle.com/community/index.php (acessado em 5/06/2006).

${ }^{18}$ A lista de organizações e grupos de auto-ajuda e auto-advocacia em diferentes países e continentes é enorme. Basta buscar no Google grupos de auto-ajuda e auto-advocacia para as diferentes doenças e transtornos para aparecer uma lista imensa de associações. 
${ }^{19}$ É necessário fazer aqui uma ressalva metodológica em relação à aplicação que se faz neste texto do conceito de "indivíduo" e também daqueles de "pessoa" e "sujeito", que não devem ser entendidos em um sentido universal e a-histórico. O "indivíduo" não é a priori uma categoria universal e a-histórica, independente dos diferentes processos de individuação e de produção do "indivíduo" contemporâneo, entendido como radicalização das formas ocidentais modernas de produção de indivíduos singularizados e naturalizados, tal como é analisado, entre outros, por Louis Dumont (1985), Foucault (1976, 1984a, 1984b), Charles Taylor (1989), Norbert Elias (1995) Alan McFarlane (1992). Entendo "pessoa", por sua vez, no sentido proposto por Marcel Mauss (2003) no seu célebre ensaio, isto é, como uma construção histórica e social. Finalmente, uso sujeito e, por derivação, "sujeito cerebral" no sentido dado por Foucault na sua história da subjetividade (Foucault, 1976, 1984a, 1984b; Ortega 1999) como uma categoria historicizada e cuja ênfase recai precisamente nas formas e nos processos de subjetivação e nas tecnologias do self usadas pelos indivíduos para a formação de diferentes "subjetividades". Existiriam assim diferentes formas de subjetividade, tipos de "sujeito" na história da subjetividade, entre elas, o "sujeito cerebral" das sociedades contemporâneas.

${ }^{20}$ A bibliografia é imensa e não pára de crescer. Ver, entre outros, Li 2003; Sailor, Ming \& Song 2006; Schwartz \& Begley 2002; Stahnisch 2003; Weiller \& Rijntjes 1999.

${ }^{21}$ Um exemplo deste deslocamento é o livro de Ansermet \& Magistretti (2004), no qual o conceito de plasticidade denota o caráter aberto à mudança e a contingência das redes neuronais, possibilitando uma aproximação entre psicanálise e neurociência.

${ }^{22}$ Embora menos relevante para o argumento que estou lançando aqui, vale a pena ressaltar que, mesmo do lado dos correlatos mentais, os dados experimentais são contraditórios. Por exemplo, um estudo dinamarquês feito com indivíduos meditando mostrou um resultado oposto ao de Newberg \& D'Aquili, isto é, aumento de atividade nos lobos parietais e diminuição nos frontais. Ver Andreson 2000.

${ }^{23}$ Em outro contexto (Ortega 2008), usei o termo "corpo fenomenológico" para ressaltar uma dimensão da corporeidade, a qual não é reduzível nem ao corpo anatomofisiológico, isto é, ao conjunto das trocas metabólicas com o ambiente que têm como objetivo a auto-regulação dos indivíduos e a continuidade da espécie, nem ao corpo como discurso ou construção simbólica. Esta dimensão está presente, entre outros, na fenomenologia corporal de Husserl, Merleau-Ponty, Erwin Strauss, Samuel Todes, Drew Leder, no pragmatismo de William James e John Dewey, na antropologia do "embodiment" de Csordas e outros, na psicanálise winnicottiana, ou nas posições ecológicas de Gibson e Reed. Todas elas enfatizam a participação do ambiente na constituição do eu corporal, afirmando o vínculo intencional com o meio, a simultaneidade e a congenialidade das experiências do eu e do mundo, a indissolubilidade do corpo e do ambiente. Nessa perspectiva, não existe divisão mente/corpo, mente/cérebro, subjetivo/objetivo. Físico e mental não são entidades metafísicas ou ontológicas estranhas entre si; são expressões diversas de um mes- 
mo corpo em contextos ambientais diferentes. Obviamente, existe uma diferença fenomênica entre o físico e o mental. Ao final, conseguimos distinguir coisas físicas de eventos mentais. Mas não se trata de uma diferença ontológica, não são propriedades intrínsecas de determinados eventos e sim descrições operacionais que designam uma determinada relação com o ambiente. No caso dos movimentos da neurodiversidade, não acredito que a solução esteja em trocar de nome e buscar a diversidade no que concerne ao mental. Quis apenas, por motivos didáticos, mostrar como "fenomenicamente" (e não ontologicamente, pois esta clivagem mental/cerebral é ilusória) o pólo mental possui uma multiplicidade dada pela imaterialidade que o pólo cerebral não possui, sem esquecer, claro, a unidade ontológica mente/corpo e sua congenialidade com o ambiente.

${ }^{24}$ Singer (2007). Sou muito grato a Enrico Valtellina por ter chamado a minha atenção para este texto, fundamental para meu argumento.

${ }^{25}$ Como já foi assinalado, a noção de neurossociabilidade permite compreender como o sujeito cerebral se torna um critério de formação de subjetividade e de agrupamento, isto é, de relações consigo e com os outros enquanto sujeitos cerebrais. Essas relações se produzem, como vimos, pela incorporação na vida dos indivíduos de "fatos objetivos" sobre si mesmos - seus corpos, mentes e cérebros - assim como pelo arsenal de produtos neuroascéticos produzidos pelas neurotecnologias e pelas diversas associações e movimentos de doentes e seus familiares, competições que testam a performance cerebral, entre outros.

${ }^{26}$ Justiça seja feita, a autocrítica está começando a ser realizada no seio do movimento da neurodiversidade. 


\section{Referências bibliográficas}

ACKERMAN, Sandra J. 2006. Hard science, hard choices. Facts, ethics and policies guiding brain science today. New York: Dana Press.

ANDRESON, Jensine. 2000. "Meditation meets behavioral medicine". Journal of Consciousness Studies, 7(1112):17-73.

ANSERMET, François \& MAGISTRETTI, Pierre. 2004. A chacun son cerveau. Plasticité neuronale et inconscient. Paris: Odile Jacob.

ANTONETTA, Susanne. 2005. A mind apart. Travels in a neurodiverse world. Tarcher: Penguin.

BAKER, Dana Lee. 2006. "Neurodiversity, neurological disability and the public sector: notes on the autism spectrum". Disability \& Society, 21(1):15-29.

BARON-COHEN, Simon. 1995. Mindblindness: an essay on autism and theory of mind. Cambridge, Massachusetts: MIT Press.

. 2002. "The extreme male brain theory of autism". Trends in Cognitive Sciences, 6(6):248-254.

BETTELHEIM, Bruno. 1967. The empty fortress. New York: Free Press.

BLUME, Harvey. 1997. "'Autism \& the Internet' or 'It's the wiring, stupid'". Disponível em: http://web.mit.edu/ comm-forum/papers/blume.html (acessado em 26/6/2007).

BRENDEL, David. 2006. Healing psychiatry: bridging the science/humanism divide. Cambridge, Mass. and London: The MIT Press.

BROWNLEE, Christen. 2006a. "Buff and brainy. Exercising the body can benefit the mind". Science News Online, 25/2/2006. Disponível em: http://www. sciencenews.org/articles/20060225/ bob10.asp (acessado em 1/06/2006).
_. 2006b. "Eat smart. Foods may affect the brain as well as the body". Science News Online, 4/3/2006. Disponível em: http://www.sciencenews.org/articles/20060304/bob8.asp (acessado em 1/06/2006).

CAPLAN, Arthur. 2005. "Would you have allowed Bill Gates to be born? Advances in prenatal genetic testing pose tough questions". Disponível em: http://www.msnbc. msn.com/id/7899821 (acessado em 9/06/2007).

CAVERSAN, Luiz. 2005. "Viva a diferença". Folha OnLine, 04/06. Disponível em: http://www1.folha.uol.com. br/folha/pensata/ult513u195.shtml (acessado em 14/12/2006).

CBS. 2006. "Retraining the brain. Doctors test drug-free methods to restore lost mental capabilities". CBS NEWS, Jan. 15, 2006. Disponível em: http://www. cbsnews.com/stories/2006/01/15/sunday/main1209916.shtml (acessado em 1/06/2006)

CORKER, Mairian. 1999. "New disability discourse, the principle of oftimization and social change". In: M. Corker \& S. French (orgs.), Disability discourse. Buckingham, Philadelphia: Open University Press. pp. 192-209.

COSTA, Jurandir Freire. 2004. O vestígio e a aura. Corpo e consumismo na moral do espetáculo. Rio de Janeiro: Garamond.

D'AQUILI, Eugene \& NEWBERG, Andrew B. 1999. The mystical mind: probing the biology of religious experience. Minneapolis: Augsburg Fortress Publishers.

DAVIS, Lennard J. 1995. Enforcing normalcy. Disability, deafness and the body. London, New York: Verso. 
DAWSON, Michele. 2004. "The misbehaviour of behaviourists". Disponível em: http://web.archive.org/ web/20051205014407/www.sentex. net/ nexus23/naa_aba.html (acessado em 02/06/2007).

DEKKER, Martijn. 2006. "On our own terms: emerging autistic culture". Disponível em: http://autisticculture. com/index.php?page $=$ articles (acessado em 05/12/2006).

DINIZ, Debora. 2007. O que é deficiência. São Paulo: Brasiliense.

DOLNICK, Edward. 1998. Madness on the couch. Blaming the victim in the heyday of psychoanalysis. New York: Simon \& Schuster.

DUMIT, Joseph. 2003. "Is it me or my brain: depression and neuroscientific facts". Journal of Medical Humanities, 24:35-48.

- 2004. Picturing personhood. Brain scans and biomedical identity. Princeton: Princeton University Press.

DUMONT, Louis. 1985. O individualismo. Uma perspectiva antropológica da ideologia moderna. Rocco: Rio de Janeiro.

EHRENBERG, Alain. 2004. "Le sujet cerebral". Esprit, 309:130-155.

ELIAS, Norbert. 1995. Über den Prozess der Zivilisation. Soziogenetische und psychogenetische Untersuchungen. Frankfurt am Main: Suhrkamp.

FEHER, Ferenc \& HELLER, Agnes. 1994. Biopolitics. Aldershot: Avebury.

FEINBERG, Edward \& VACCA, John. 2000. "The drama and trauma of creating policies on autism: critical issues to consider in the new millenium". Focus on Autism and Other Developmental Disabilities, 15(3):130-137.

FOMBONNE, Eric. 2003. "Modern views on autism". Canadian Journal of Psychiatry, 48(8):503-506.

FOUCAULT, Michel. 1976. La volonté de savoir. Paris: Gallimard.
- 1984a. L' usage des plaisirs. Paris: Gallimard. -1984b. Le souci de soi. Paris: Gallimard.

- 1997. Il faut défendre la société. Course at the Collège de France (1976). Paris: Gallimard-Seuil.

- 1999. Les anormaux. Course at the Collège de France (1974-1975). Paris: Gallimard- Seuil.

FRANZEN, Jonathan. 2001. The corrections. New York: Farrar, Straus \& Giroux.

FREEMAN, Betty Jo \& CRONIN, Pegeen. 2002. "Diagnosing autism spectrum disorder in young children: an uptade source". Infants and Young Children, 14(3):1-10.

FRITH, Uta (org.). 1991. Autism and Asperger Syndrome. Cambridge: Cambridge University Press.

GLANNON, Walter. 2007. Bioethics and the brain. New York: Oxford University Press.

HACKING, Ian. 2006. "What is Tom saying to Maureen?". London Review of Books, 28 (9). Disponível em http:// www.lrb.co.uk/v28/n09/hack01_html (acessado em 10/05/2007).

HAGNER, Michael \& BORCK, Cornelius. 2001. "Mindful practices: on the neurosciences in the twentieth century". Science in Context, 14:507-510.

HARMON, Amy. 2004a. "Adults and autism; an Answer, but not a cure, for a social disorder". New York Times, April 29. . 2004b. "Neurodiversity forever; the disability movement turns to brains". New York Times, May 9. . 2004c. "How about not 'curing' us, some autistics are pleading". New York Times, Dec. 20.

HEALY, David. 2002. The creation of psychopharmacology. Cambridge, MA: Harvard University Press.

HELLER, Agnes. 1995. "Achtung Europa!, Über die Biologisierung des Politischen", Disponível em: www.han- 
nah-arendt.de/verein/publikationen heller.html (acessado em 1/05/2004).

HORGAN, John. 2003. Rational mysticism. Dispatches from the border between science and spirituality. Boston and New York: Houghton Mifflin Company.

ILLES, Judy (org.). 2006. Neuroethics. Defining the issues in theory, practice, and policy. New York: Oxford University Press.

JOYCE, Kelly. 2005. "Appealing images: magnetic resonance imaging and the production of authoritative knowledge". Social Studies of Science, 35:437-462.

KANNER, Leo. 1943. "Autistic disturbances of affective contact". Nervous Child, 2:217-250.

LAGE, Amarílis. 2006. "Movimento diz que autismo não é doença". Folha OnLine, 27/07/2006. Disponível em: http://www1.folha.uol.com.br/folha/equilibrio/noticias/ult263u4159. shtml (acessado em 14/12/2006).

LI, Shu-Chen. 2003. "Biocultural orchestration of developmental plasticity across levels: the interplay of biology and culture in shaping the mind and behavior across the life span". Psychological Bulletin, 129(2):171-194.

LYNCH, Zack. 2004. "Neurotechnology and society (2010-2060)". Annals of the New York Academy of Science, 1013:229-233.

LUHRMANN, Tanya M. 2000. Of 2 min$d s$ : the growing disorder in american psychiatry. New York: Alfred A. Knopf. MAUSS, Marcel. 2003. "Uma categoria do espírito humano: a noção de pessoa, a de 'eu'". In: Sociologia e antropologia. São Paulo: Cosac \& Naify. pp. 367-397.

McFARLANE, Alan. 1992. "On individualism". Proceedings of the British Academy, 82:171-199.
NELSON, Amy. 2004. "Declaration from the autism community that they are a minority group", November 18 . Disponível em: http://www.prweb. com/releases/2004/11/prweb179444. htm (acessado em 05/12/2006).

NEWSCHAFFER, Craig .J. \& CURRAN, Laura Kresch. 2003. "Autism: an emerging public health problem". Public Health Rep, 118(5):393-399.

NOGUEIRA, Tânia. 2007. "Um novo olhar sobre o autismo". ÉPOCA, pp.76-85, 11.06. Disponível em: http://revistaepoca.globo.com/Revista/Epoca/ 0,,EDG77644-8055-473-1,00.html (acessado em 11/06/2007).

ORTEGA, Francisco. 1999. Amizade e estética da existência em Foucault. Rio de Janeiro: Graal. . 2006. "Cérebro best-seller". O Globo, Caderno Prosa \& Verso, p.5, Rio de Janeiro, 29 jul.

- 2007. "Mapping the cerebral subject in contemporary culture". RECIIS Electronic Journal of Communication Information \& Innovation in Health, 1(2):255-259.

- 2008. O corpo incerto. Corporeidade, tecnologias médicas e cultura contemporânea. Rio de Janeiro: Garamond.

. \& VIDAL, Fernando. 2006. "O sujeito cerebral. Novo paradigma defende abordagem multidisciplinar para compreender a experiência humana". Scientific American Brasil, 52:20.

POLLACK, Richard. 1997. The creation of Dr. B. A biography of Bruno Bettelheim. New York: Simon \& Schuster.

RABINOW, Paul. 1992. "Artificiality and enlightenment: from sociobiology to biosociality". In: J. Crary \& S. Kwinter (orgs.). Incorporations. New York: Zone Books. pp. 234-252.

RODRIGUEZ, Paul. 2006. "Talking brains: a cognitive semantic analysis of an emerging folk neuropsychology". 
Public Understanding of Science, 15(3):301-330.

ROSE, Nikolas. 2003. "Neurochemical selves". Society, 41(1):46-59.

. 2006. "Disorders without borders? The expanding scope of psychiatric practice". Biosocieties, 1(4):465484.

ROSE, Steven. 2005. The future of the brain. The promise and perils of tomorrow's neuroscience. New York: Oxford University Press.

ROSENBERG, Charles E. 2002. "The tyrannt of diagnosis: specific entities and individual experience". The Milkbank Quarterly, 80(2):237-260.

- 2006. "Contested boundaries: psychiatry, disease, and diagnosis". Perspectives in Biology and Medicine, 49(3):407-424.

RUSSO, Jane A. 2005. "Do desvio ao transtorno: a medicalização da sexualidade na nosografia psiquiátrica contemporânea". In: A. Pscitelli; M. F. Gregori; S. Carrara (orgs.), Sexualidade e saberes: convenções e fronteiras. Rio de Janeiro: Garamond. pp. 95-114.

- \& HENNING, Marta. 1999. "O sujeito da 'psiquiatria biológica' e a concepção moderna de pessoa". Antropolítica, 6:39-55.

- \& VENANCIO, Ana Teresa. 2006. "Classificando as pessoas e suas perturbações: a 'revolução terminológica' do DSM III". Revista Latino-Americana de Psicopatologia Fundamental, IX:460-483.

SAILOR, Kurt A.; MING, Guo-li \& SONG, Hongjun. 2006. "Neurogenesis as a potential therapeutic strategy for neurodegenerative diseases". Expert Opinion on Biological Therapy, 6(9):879-890.

SCHWARTZ, Jeffrey \& BEGLEY, Sharon. 2002. The mind and the brain: neuroplasticity and the power of mental force. New York: HarperCollins.
SHAPIRO, Joseph. 2005. "Autism movement seeks acceptance, not cures". Disponível em: http://www.npr.org/templates/story/story.php? storyId $=5488463$ (acessado em 05/12/2006).

SILBERMAN, Steve. 2001. "The geek syndrome". Wired, Issue 9/12, Dec. Disponível em: http://www.wired.com/wired/ archive/9.12/aspergers.html (acessado em 5/12/2006).

SINCLAIR, Jim. 1993. "Don't mourn for us". Voice, 1 (3). Disponível em: http://ani.autistics.org/dont_mourn. htlm (acessado em 05/12/2006).

SINCLAIR, John. 2005. "Autism network international: the development of a community and its culture". Disponível em: http://web.syr.edu/ jisincla/ History_of_ANI.html (acessado em 05/12/2006).

SINGER, Emily. 2005. "Exercising the brain. Innovative training software could turn back the clock on aging brains". Technology Review, Nov. 21. Disponível em: http://www.technologyreview.com/InfoTech-Software/wtr_15914,300,p1.html (acessado em 1/06/2006).

SINGER, Judy. 1999. "Why can't you be normal for once in your life?' From a 'problem with no name' to the emergence of a new category of difference". In: M. Corker \& S. French (orgs.). Disability discourse. Buckingham, Philadelphia: Open University Press. pp. 59-67.

. 2007. "Light and dark. Correcting the balance". Disponível em: http://www. neurodiversity.com.au (acessado em 1/06/2007).

STAHNISCH, Frank W. 2003. "Making the brain plastic: early neuroanatomical staining techniques and the pursuit of structural plasticity, 1910-1970?". Journal of the History of the Neurosciences, 12(4):413-435.

SWAIN, Joan \& CAMERON, Colin. 1999. "Unless otherwise stated: discourses of labeling and identity in coming 
out". In: M. Corker \& S. French (orgs.), Disability discourse. Buckingham, Philadelphia: Open University Press. pp. 68-78.

TAYLOR, Charles. 1989. Sources of the self: the making of modern identity. Cambridge, MA: Harvard University Press.

VALENSTEIN, Elliot S. 1998. Blaming the brain. The truth about drugs and mental health. New York: The Free Press.

VIDAL, Fernando. 2005. "Le sujet cérébral: une esquisse historique et conceptuelle". Psychiatrie, Sciences Humaines, Neurosciences, 3(11):37-48.

WEILlER, Cornelius \& RIJNTJES, Michel. 1999. "Learning, plasticity, and recovery in the central nervous system". Experimental Brain Research, 128(12):134-138.

WEINTRAUB, Kit. s/d. "Letter to the NY Times from Kit Weintraub". The schafer autism report. Disponível em: http://www.sarnet.org/ltr/weintraub105.htm (acessado em 1/12/2006). . 2005. "A mother's perspective", Disponível em: http://web.archive.org/ web/20051216174906/http://asatonline. org/resources/library/moms_perspective.html (acessado em 25/06/2007).

WICKELGREN, Ingrid. 2005. "Autistic brains out of synch?". Science, 308: 1856-1858.

WING, Lorna. 1997. "The history of ideas on autism: legends, myths and reality". Autism, 1:13-23. 


\section{Resumo}

Este artigo analisa o movimento da neurodiversidade organizado basicamente por autistas chamados de alto funcionamento que consideram que o autismo não é uma doença a ser tratada, mas uma diferença humana, a qual deve ser respeitada como outras diferenças. O movimento da "neurodiversidade" deve ser inserido em um marco sociocultural e histórico mais amplo que incorpore o impacto crescente no imaginário cultural dos saberes e das práticas neurocientíficas com o paradigma do sujeito cerebral e a expansão da neurocultura. No contexto do sujeito cerebral, o cérebro responde por tudo o que outrora costumávamos atribuir à pessoa e vem se tornando um critério biossocial de agrupamento fundamental. $\mathrm{O}$ artigo mostra como uma ideologia solipsista, reducionista e cientificista o sujeito cerebral - pode servir de base para a formação de identidade e de redes de sociabilidade e comunidade.

Palavras-chave Neurodiversidade, Sujeito cerebral, Autismo, Classificações psiquiátricas

\section{Abstract}

This article analyzes the neurodiversity movement, organized mostly by so-called high-functioning autists, who consider that autism is not a disease to be treated, but rather a human difference that should be respected alongside other differences. The "neurodiversity" movement must be set within a wider sociocultural and historical field that incorporates the growing impact of neuroscientific knowledge and practices in the cultural imagination with the paradigm of the cerebral subject and the expansion of neuroculture. In the context of the cerebral subject, the brain accounts for all that we used to attribute to the person, and it is becoming a fundamental criterion for biosocial grouping. The article shows how a solipsist, reductionist and scientificist ideology the cerebral subject - can act as the basis for the formation of identity and networks of sociability and community. Key words Neurodiversity, Cerebral subject, Autism, Psychiatric classifications 